\title{
Meios de acesso à literatura para pessoas com cegueira: Braille ou Áudio-livro?
}

\author{
Vivian Santos* \\ Amanda Cristina dos Santos Pereira** \\ Paulo Eduardo Zorel*** \\ Ailton Barcelos da Costa**** \\ Maria Amelia Almeida***** \\ Marcia Duarte ****** $^{* * 2}$
}

\section{Resumo}

O acesso à literatura por pessoas cegas vem acontecendo, prioritariamente, através do sistema braille. Devido ao avanço e a popularizaçáo da tecnologia, tem ocorrido uma procura maior pela literatura em áudio em nosso país. Dessa forma, o estudo surgiu do questionamento de como o acesso à literatura por pessoas cegas vem ocorrendo, tendo como objetivo analisar as implicaçóes do uso desses meios de acesso por pessoas cegas. O instrumento de coleta de dados consistiu em um roteiro de entrevista semiestruturado, que foi aplicado a cinco pessoas cegas. Estas, por sua vez, foram gravadas e transcritas, com os dados agrupados por blocos temáticos, em tabelas e gráficos, para análise qualitativa e quantitativa. Os resultados indicaram que os sujeitos mais velhos, não dão preferência por nenhum dos meios, pois de acordo com os mesmos, ambos têm suas vantagens e desvantagens. Já os sujeitos mais jovens, revelaram preferência pelo áudio e pelo braille. Conclui-se que, ambos os meios de acesso estudados possuem suas implicaçóes positivas e negativas, de tal forma que as pessoas cegas tendem a optar por ambos, mas apesar disso, em termos de preferência, o braille prevalece drasticamente.

Palavras-chave: Deficiência visual; Sistema braille; Áudio-livro.

\footnotetext{
* Mestranda em Educação Especial pela Universidade Federal de São Carlos, São Carlos, São Paulo, Brasil.

** Mestranda em Educação Especial pela Universidade Federal de São Carlos, São Carlos, São Paulo, Brasil.

*** Graduado em em Educação Especial pela Universidade Federal de São Carlos, São Carlos, São Paulo, Brasil.

**** Doutorando em Educação Especial pela Universidade Federal de São Carlos, São Carlos, São Paulo, Brasil.

***** Professora doutora da Universidade Federal de São Carlos, São Carlos, São Paulo, Brasil.

*******Professora doutora da Universidade Federal de São Carlos, São Carlos, São Paulo, Brasil.
} 


\section{Literature access means for people with blindness: Braille or audiobook?}

\section{Abstract}

Access to literature for blind people has been going primarily through the braille system. Due to the advancement and popularization of technology, there has been an increased demand for literature in audio in our country. Thus, the study emerged from questioning of how access to literature for blind people has been occurring, and to analyze the implications of using these means of access for blind people. The data collection instrument consisted of a semi structured interview script, which was applied to five blind people. These, in turn, were recorded and transcribed, with the data grouped by thematic blocks in tables and graphs for qualitative and quantitative analysis. The results indicated that older subjects do not give preference to any of the means, because according to them, both have their advantages and disadvantages. The younger subjects demonstrated preference for the audio and braille. We conclude that both means of access studied haveits positive and negative implications, such that blind people tend to opt for both, but nevertheless, in terms of preference, braille prevails dramatically. We conclude that both means of access have studied its positive and negative implications, such that blind people tend to opt for both, but nevertheless, in terms of preference, braille prevails dramatically.

Keywords: Visual impairment; Braille system; Audiobook.

\section{Introdução e justificativa}

Este estudo surgiu a partir de indagaçóes a respeito de como vem ocorrendo o acesso da pessoa cega à literatura, ou à leitura de maneira geral, considerando a era da tecnologia, e a sua influência neste processo.

Destarte, abordaram-se questóes referentes apenas a pessoas cegas, tanto congênitas quanto adquiridas, e, para tal, tem-se um breve histórico da deficiência visual.

Primeiramente, no que tange a definição científica da deficiência visual, esta se modificou bastante com o passar do tempo, sendo que a atual foi definida no Conselho Internacional de Oftalmologia, que ocorreu em 2002, em Sidney (Austrália), a qual divide a deficiência visual em cegueira (perda total da visão), baixa visão (graus menores de perda de visão), visão diminuída (perda de funções visuais, que pode ser avaliado quantitativamente), visão funcional (capacidade da pessoa de usar a visão nas Atividades de Vida Diária) e perda de visão (é um termo geral, usado em qualquer um dos casos de deficiência visual) (REIS; EUFRÁSIO; BAZON, 2010).

Já do ponto de vista educacional, segundo Barraga (1985), pessoas cegas são aquelas que possuem a percepção de luz insuficiente para enxergar, fazendo-se necessário a utilização do sistema braille para aprender.

Ao abordar o processo histórico da deficiência visual, como em relação à sua educação, pouco se tem falado a respeito do cego antes de século XVII, e o que existe 
são generalizaçóes como de Franco e Dias (2005), colocando o cego no pior dos cenários, o que nem sempre foi verdade, conforme Martínez (1991).

Nesse sentido, o primeiro programa educativo documentado para cegos se estabeleceu em 970 d. C. na Universidade de Al-Ashar, no Egito Antigo (GARCIA; CAÑADAS, 2009). Já Martínez (1991) diz que no Japão, século III a. C., o príncipe Itoyashu, cego, começou a ensinar literatura chinesa e japonesa, música e filosofia a outros companheiros cegos. Ainda segundo este autor, os cegos foram os primeiros pedagogos, ensinando música no século III a. C. na Roma Antiga.

Martínez (1991) também diz que no século VIII, no Império Bizantino, os cegos estudavam direito grego na Universidade de Constantinopla. Em seguida, há relato que, no século $\mathrm{X}$, centenas de estudantes cegos frequentavam a Universidade de El Ashar, no Cairo e em Alexandria, e que mais tarde, no século XIV, o cego árabe Zain-din Al-Amidi criou um sistema de leitura e de escrita em relevo por meio de pontos, o qual não teria sido difundido no ocidente. Esta escrita para pessoas cegas só começou a avançar na Europa e no ocidente de maneira ampla com Valentin Haüy, que fundou em Paris em 1784, o Instituto Nacional dos Jovens Cegos, sendo fundadas, em seguida, às primeiras escolas abertas para cegos, como a de Liverpool em 1791, a de Londres em 1799, a de Viena em 1805 e a de Berlin em 1806 (MAZZOTTA, 2005).

Ainda segundo Mazzotta (2005), em 1829, Louis Braille criou o que nos dias atuais é conhecido como o sistema braille.

No que tange o Brasil, foi fundado por D. Pedro II, em 12 de setembro de 1854, o Imperial Instituto dos Meninos Cegos, que passou a ser chamado de Instituto Benjamin Constant (IBC), em 24 de Janeiro de 1891, sendo responsável por diversas açóes no país relacionadas às pessoas cegas, como exemplo, a edição da Revista Brasileira para Cegos em 1942, a instalação da imprensa braille em 1943, e a distribuição de livros em braille para pessoas cegas (MAZZOTTA, 2005). Além deste, continua o autor, outras instituiçôes voltadas às pessoas cegas foram fundadas, como a Fundação para o Livro do Cego no Brasil, instalada em São Paulo no ano de 1946, graças aos esforços de Dorina Nowill, que em 1990 passou a ser denominada Fundação Dorina Nowill para Cegos.

Ao considerar a história dos livros e da leitura, Paletta, Watanabe e Penilha (2007) apontam que, com o tempo, o papel substituiu o pergaminho, os bytes substituíram os manuscritos, as telas substituíram o papel, e assim, os livros de papel perderam a novidade, mas não a importância.

Estes autores ainda destacam que as gravaçóes de obras literárias e teatrais surgiram pouco depois da Primeira Guerra Mundial, para entreter soldados que perderam a visão durante as batalhas, e assim, o que era um produto para cegos, foi se tornando uma opçáo também para pessoas que não tinham tempo para ler livros tradicionais.

Com o advento das tecnologias digitais, os áudio-livros surgem como um novo tipo de produto que possui tudo para revolucionar o hábito de leitura, pois 
este formato surgiu, de fato, como mercadoria a partir de 1980, com a popularização desse formato, e chega a movimentar, hoje, mais de US\$ 800 milhóes anualmente; porém, no Brasil foi contabilizado poucos títulos durante a década passada, e é visto como um auxílio, predominantemente para deficientes visuais (PALETTA; WATANABE; PENILHA, 2007).

Passando a uma revisão dos trabalhos publicados, diretamente relacionados à pesquisa, não foi encontrado nenhum artigo diretamente ligado a esta temática específica. Para tal, recorreu-se ao "Google Acadêmico", ao "Catálogo de Publicaciones de Servicios Sociales da ONCE (Organización Nacional de Ciegos Españoles)", e ao periódico brasileiro especializado, Revista Benjamin Constant, com os seguintes descritores: "áudio-livro", "braile", "meios de acesso", "deficiente visual", "literatura" e "cegueira", para o período compreendido de 1993 e 2013, utilizados isoladamente e em associação, tanto em português como em espanhol. Já, com relaçáo aos temas semelhantes, foi encontrado, por meio do "Google Acadêmico" o artigo de Dallabrida e Lunardi (2008) que aborda o acesso aos livros em braille, sua materialidade, circulação, práticas e usos, disponíveis em uma biblioteca, para os sujeitos com deficiência visual.

Já, através do Catálogo de Publicaciones de Servicios Sociales, foram encontrados três trabalhos, sendo esses, o de Rueda (1995), que estuda como a informação contextual pode ajudar em uma leitura mais rápida do sistema braille, trazendo como resultado, que esta facilidade em relacionar palavras a contextos pode facilitar a leitura para os cegos, tornando-a mais rápida, e que esta mesma facilidade está intimamente ligada também ao nível de escolarização dos mesmos. Já o segundo Hertlein (1999), o ensino escolar (seja em instituiçóes especializadas ou em escolas regulares) de pessoas com deficiência visual deve conter o ensino, treino e uso do sistema braille, reafirmando a ideia de que com os avanços tecnológicos, este não pode ser descartado da educação de pessoas com deficiência visual.

Por fim, o terceiro, de autoria de Cierco (2002), identifica as diversas desvantagens encontradas por usuários do braille, que podem ser vistas também nos dias de hoje em nosso país, como o acesso a produtos de informática e equipamentos adaptados, que dificilmente são encontrados no mercado.

\section{Objetivos}

\section{Objetivo Geral}

Analisar os meios de acesso à literatura, utilizados por pessoas cegas.

\section{Objetivos Específicos}

Averiguar os pontos positivos e negativos da utilização dos meios de acesso à literatura direcionada às pessoas cegas;

Verificar a utilização e apreciação da linguagem em braille e de áudio-livros, identificando se há diferença entre cegos congênitos e adquiridos;

Enumerar as implicações referentes à utilização de braille e áudio-livros; 
Conhecer a influência da dificuldade de acesso à linguagem em braille e de áudio-livros.

\section{Método}

\section{Delineamento}

Foi utilizada a abordagem diferencial, que tem como objetivo investigar a natureza e as causas da expressão das variaçôes dentro de uma população (LOWENTHAL; ARAÚJO, 2006). Um dos pontos mais importantes dessa abordagem é a cuidadosa descrição das características da população estudada, bem como a busca de correlatas e possíveis causalidades, que se referem exatamente ao motivo que alguns indivíduos se afastam da média em relação às outras (WARREN, 1994).

As vantagens desse tipo de abordagem com o sujeito com deficiência visual, segundo Warren (1994), se baseiam na grande variação de desenvolvimento que se tem observado nesta população, de maneira particular e, também, na importância do conhecimento adquirido a partir desse enfoque, onde se pode melhor estabelecer intervençóes apropriadas para as particularidades apresentadas dentro de suas características gerais.

Como método de pesquisa, utilizou-se o modelo misto, que consiste, segundo Sampiere, Collado e Lúcio (2006), na combinação dos modelos qualitativo e quantitativo, devido à possibilidade de desenvolver uma pesquisa com dados estatísticos, já que com a utilização do método quantitativo torna-se possível a coleta de dados concretos, estabelecendo-se com exatidão os padróes de resposta dos participantes, e que, com o modelo qualitativo, torna-se possível uma melhor interpretação das questôes da pesquisa.

\section{Local}

A coleta de dados foi realizada no município de São Carlos/SP, na instituição de ensino superior público, Universidade Federal de Sáo Carlos.

\section{Participantes}

Foram participantes da pesquisa, cinco pessoas com cegueira, adquirida ou congênita, a partir de 16 anos, que estivessem cursando o ensino médio, curso prévestibular, graduação ou pós-graduação, desconsiderando o gênero, a profissão e a classe social dos mesmos.

\section{Equipamentos/Materiais}

Os materiais utilizados compreenderam em folha de sulfite A4, lápis, caneta, borracha, além de gravador, notebook e impressora.

\section{Instrumentos}

O instrumento de coleta de dados consistiu em um roteiro de entrevista semiestruturada, desenvolvido pelos autores da pesquisa, composto por seis blocos temáticos, sendo estes: 
- caracterização do entrevistado: visando conhecer um pouco sobre o sujeito;

- conhecimento sobre o braille: abordando questóes referentes à escrita, alfabetização e leitura em braille que o entrevistado, por ventura, possua;

- acesso ao braille: objetivando identificar os meios de acesso ao braille que o entrevistado possui e/ou conhece;

- conhecimento sobre áudio-livros: buscando saber se o entrevistado conhece áudios-livros, se os utiliza e se considera que a narração do interlocutor influencia na interpretação do conteúdo;

- acesso ao áudio-livro: almejando identificar os meios de acesso a áudio-livros que o entrevistado possui e/ou conhece;

- preferência quanto à leitura: tratando da preferência do entrevistado quanto à leitura por meio do sistema braille ou áudio-livros, tendo como objetivo central identificar as vantagens e desvantagens destes recursos.

\section{Procedimentos de coleta e análise de dados}

Cada participante foi entrevistado uma única vez, individualmente. A entrevista foi gravada em áudio. Após a coleta, os dados foram transcritos e organizados em tabelas.

Para a análise dos dados, foram criados tabelas e gráficos, possibilitando maior compreensão dos dados quantitativos e qualitativos, tomando como referência a literatura levantada a respeito.

\section{Procedimentos éticos}

Foi entregue aos participantes um termo de consentimento livre e esclarecido, o qual foi lido pelos pesquisadores e pelo participante, só havendo a realização da entrevista após a assinatura deste termo por ambos os indivíduos, respeitando todos os procedimentos éticos.

No caso de entrevistados com idade inferior a 18 anos, o termo de consentimento livre e esclarecido foi lido para o participante acompanhado de um responsável, sendo solicitado que a assinatura fosse concedida por este responsável, o qual também acompanhou a entrevista na íntegra.

Além disso, destacou-se o fato de que a identidade dos participantes seria resguardada, e que as informaçóes obtidas seriam utilizadas apenas para fins de divulgação científica.

\section{Resultados e Discussão}

Começando com a caracterizaçáo dos participantes envolvidos na pesquisa, $40 \%$ possuem idade entre 30 e 40 anos, $40 \%$ entre 20 e 30, e $20 \%$ entre 16 e 20 anos. Já, no que tange à escolarização, 20\% possuíam Ensino Médio Incompleto, 
20\% Ensino Médio Completo, 20\% Ensino Superior Incompleto, e 40\% com Ensino Superior Completo. Quanto ao tipo de cegueira, pode-se perceber que $40 \%$ dos indivíduos possuíam cegueira congênita, e $60 \%$ com cegueira adquirida, distribuídos conforme tabela abaixo:

Tabela 1 - Causa e idade da perda da visão dos participantes

\begin{tabular}{l|l|l|l|l|l}
\hline \multicolumn{6}{l}{ Causa e idade (quando adquirido) da perda da visáo } \\
\hline & E1 & E2 & E3 & E4 & E5 \\
\hline Causa & $\begin{array}{l}\text { Acidente } \\
\text { de carro }\end{array}$ & Desconhecido & $\begin{array}{l}\text { Retinose } \\
\text { pigmentar }\end{array}$ & $\begin{array}{l}\text { Toxoplasmose } \\
\text { na gravidez }\end{array}$ & $\begin{array}{l}\text { Má } \\
\text { formação } \\
\text { cerebral }\end{array}$ \\
\hline Idade & 20 anos & Congênito & Congênito & 10 anos & 13 anos \\
\hline
\end{tabular}

Fonte: os autores.

Com os dados acima, pode-se perceber a prevalência de doenças no que diz respeito à perda da visão, o que pode ocorrer devido ao fato do Brasil ser um país em desenvolvimento, como explicita Temporini e Kara-José (2004), ao apontarem que, tomando por base dados populacionais de 1993, a Organização Mundial da Saúde (OMS) comparou a prevalência de cegueira com dados econômicos de 229 países, onde os resultados mostraram que o desenvolvimento econômico de cada país estava associado à respectiva prevalência de cegueira.

Em sequência, se têm os dados referentes ao conhecimento sobre o sistema braille, onde foram analisados, primeiramente se os participantes sabiam utilizar este sistema, sendo que foi constatado que todos os participantes aprenderam a utilizar o sistema braille. Este processo ocorreu, com todos os sujeitos estudados, em instituiçóes especializadas em deficiência visual, havendo variaçáo média de idade, como se pode verificar na Tabela 2 .

Tabela 2 - Relação da idade e do local onde os participantes aprenderam o sistema de escrita em braille

\begin{tabular}{l|l|l|l|l|l}
\hline & E1 & E2 & E3 & E4 & E5 \\
\hline Idade & 26 anos & 7 anos & 10 anos & 11 anos & 17 anos \\
\hline Local & CIADEVA & CIADEVA & $\begin{array}{l}\text { Internato } \\
\text { Padre Chico }\end{array}$ & DADV & DADV \\
\hline
\end{tabular}

Fonte: os autores.

$\mathrm{Na}$ tabela acima, pode-se constatar que os participantes E1 e E2 aprenderam a utilizar o sistema braille no CIADEVA (Centro de Integração e Apoio ao Deficiente Visual Auditivo), esta instituição é voltada ao atendimento às pessoas com deficiência visual e/ou auditiva, e está localizada em Taboão da Serra/ SP. Já o E3 aprendeu a utilizar o sistema no Instituto de Cegos Padre Chico, o qual consiste em uma entidade sem fins lucrativos que mantém uma escola de ensino fundamental, totalmente gratuita, em São Paulo, para pessoas cegas e com baixa visão. Já, os participantes E4 e E5, 
aprenderam a utilizar o sistema braile no DADV (Deficientes Auditivos e Deficientes Visuais), a qual consiste em uma instituição localizada em Araras, especializada em pessoas com deficiência auditiva e visual.

Quanto à forma de escrita em braille, dos cinco entrevistados, quatro citaram tanto a reglete quanto a máquina de escrever em braille e um citou somente a máquina de escrever em braille.

Sobre o acesso ao braille, foi analisado se os participantes conheciam locais onde existem textos disponíveis em braille. A resposta foi positiva em $100 \%$ dos casos. Já, quanto a locais onde há a possibilidade de impressão de outros materiais gratuitamente, houve somente uma resposta negativa.

Quanto aos meios utilizados para escrever em braille, houve uma variação nas respostas, havendo prevalência da máquina em escrever em braille.

Porém, para Torres, Mazzoni e Mello (2007), nem todas as pessoas cegas optam em utilizar o braille. Para estes autores, na comparação da fluência da leitura em braille entre pessoas que foram alfabetizadas através deste sistema e outras que o aprenderam na idade adulta, as pessoas que têm maior fluência na leitura sentem-se mais à vontade com a leitura de textos impressos em braille, mesmo que esses textos sejam longos, enquanto as outras preferem utilizar o braille apenas para pequenos textos.

Da mesma forma que foi analisado o conhecimento sobre o braille dos participantes, analisou-se o conhecimento dos mesmos quanto ao áudio-livros, onde se pode perceber que a maioria dos participantes sabe da existência do áudio-livro, havendo uma grande maioria que desconhece a maneira como se transforma um livro on-line em áudio-livro, bem como, que a variação na influência da qualidade do livro e da entonação da voz do narrador é a mesma, sendo que o motivo da influência da entonação da voz explicitado pelos participantes é semelhante.

Sobre o acesso a áudio-livros, levou-se primeiramente em consideração se estes possuem acesso a um computador e à internet, pois caso não possuíssem, seria complexo utilizar este recurso. Todos os participantes responderam positivamente a estas duas perguntas. Com isso, analisou-se se eles conhecem locais onde se tem áudio-livros disponíveis, se o utilizam e onde os obtém.

Sendo assim, tem-se a tabela 3 , a qual é referente à utilização, bem como a frequência da mesma, de áudio-livros e também aos locais onde os participantes obtém estes áudio-livros. 
Tabela 3 - Utilização de áudio-livros e locais onde obtém.

\begin{tabular}{|c|c|c|c|c|c|}
\hline & E1 & E2 & E3 & E4 & E5 \\
\hline Utilizaçấo & Utiliza & Utiliza pouco & Não utiliza & Utiliza & Utiliza \\
\hline $\begin{array}{l}\text { Onde } \\
\text { obtém }\end{array}$ & $\begin{array}{l}\text { CIADEVA, } \\
\text { SENAC, Santo } \\
\text { Amaro e Centro } \\
\text { Cultural de São } \\
\text { Paulo }\end{array}$ & $\begin{array}{l}\text { Não } \\
\text { especificou } \\
\text { onde obtém. }\end{array}$ & $\begin{array}{l}\text { Não utiliza, mas } \\
\text { sabe que é } \\
\text { possível obter no } \\
\text { CIADEVA e na } \\
\text { Fundação Dorina } \\
\text { Nowill }\end{array}$ & $\begin{array}{l}\text { Não } \\
\text { sabe } \\
\text { onde } \\
\text { obter. }\end{array}$ & $\begin{array}{l}\text { Não } \\
\text { sabe } \\
\text { onde } \\
\text { obter. }\end{array}$ \\
\hline
\end{tabular}

Fonte: os autores.

Todas as questôes elucidadas acima visavam introduzir o tema da questão de pesquisa, o qual é respondido nos dados contidos abaixo, ou seja, aqueles referentes à preferência do meio de acesso à literatura utilizado pelas pessoas cegas bem como suas implicaçóes positivas e negativas.

Sobre a preferência do meio de acesso, notou-se que o braille tem grande destaque, estando presente em $80 \%$ das respostas, como é possível analisar no gráfico abaixo.

Gráfico 1 - Preferência do meio de acesso.

\section{Preferência do meio de acesso}

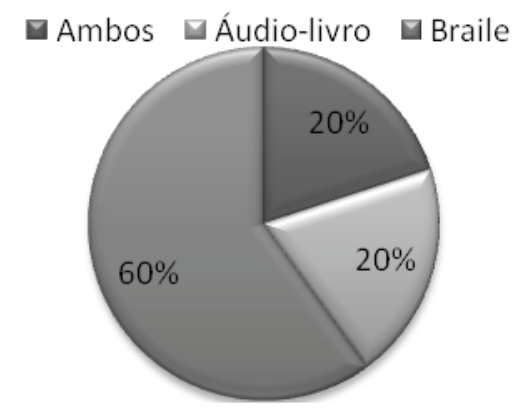

Fonte: os autores.

Sobre as implicaçôes positivas da utilização do braille, houve a prevalência pelo conhecimento da gramática, tendo havido também respostas sobre a confiabilidade, o desenvolvimento da coordenação motora fina, a possibilidade de reler com facilidade algum determinado trecho, como ilustra a tabela 4 .

Tabela 4 - Implicaçôes positivas da utilização do braille.

\begin{tabular}{l|l}
\hline E1 & Confiabilidade, conhecimento da gramática e da ortografia \\
\hline E2 & Conhecimento da gramática \\
\hline
\end{tabular}




\begin{tabular}{c|l}
\hline E3 & $\begin{array}{l}\text { Conhecimento da gramática, desenvolvimento da coordenaçáo motora fina, tato, } \\
\text { etc. }\end{array}$ \\
\hline E4 & Conhecimento da gramática, o que gera facilidade ao escrever redaçôes \\
\hline E5 & $\begin{array}{l}\text { Possibilidade de poder reler com facilidade trechos que não compreendeu gerando } \\
\text { maior compreensáo do que foi lido }\end{array}$ \\
\hline
\end{tabular}

Fonte: os autores.

Sobre as implicaçóes negativas da utilização do braille, foi apontada principalmente a velocidade da leitura (lenta) e a dificuldade de se carregar grande quantidade de material impresso em braille, devido ao seu volume e peso. Outras implicaçôes foram apontadas, havendo também participantes que não vislumbram nenhuma implicação negativa na utilização do braille, como mostra a tabela 5 .

Tabela 5 - Implicaçóes negativas da utilização do braille.

\begin{tabular}{l|l|l|l|l}
\hline \multicolumn{5}{c}{ Implicaçóes negativas da utilizaçáo do braille } \\
\hline E1 & E2 & E3 & E4 & E5 \\
\hline $\begin{array}{l}\text { Leitura lenta, } \\
\text { quantidade } \\
\text { grande de } \\
\text { folhas. }\end{array}$ & $\begin{array}{l}\text { quantidade de } \\
\text { folhas. }\end{array}$ & $\begin{array}{l}\text { Pouco material em } \\
\text { braille, quantidade } \\
\text { de folhas e desgaste } \\
\text { natural. }\end{array}$ & & Nenhuma. \\
\hline
\end{tabular}

Fonte: os autores.

Torres, Mazzoni e Mello (2007) discutem que as pessoas cegas que não utilizam o braille são devido ao fato de não conseguirem desenvolver a habilidade tátil que é necessária para essa forma de leitura ou porque perderam parte dessa habilidade tátil (situação que ocorre, por exemplo, quando a irrigação sanguínea nas extremidades dos dedos é insuficiente).

Já quanto às implicaçôes positivas da utilização do áudio-livro, os itens mais apontados foram em relação à portabilidade e a agilidade da leitura. Dessa forma, as implicaçôes positivas vão todas ao encontro de Paletta, Watanabe e Penilha (2007).

Sobre as implicaçóes negativas, diferentemente do que os pesquisadores acreditavam no início da pesquisa, somente foi citado um único fator, sendo este o desconhecimento da gramática.

Apesar de ter sido citado apenas um aspecto negativo em relação ao áudio -livro, este é de extrema relevância e pode-se considerar que seja um aspecto mais preocupante do que os apontados em relação ao braille, pois, considera-se que as pessoas cegas devam se apropriar das normas ortográficas tanto quanto as videntes, para que não sejam prejudicadas no que tange a sua autonomia financeira, por estar diretamente relacionada com o sucesso acadêmico e profissional do indivíduo.

Seguem as implicaçóes positivas e negativas, como ilustra a tabela a seguir. 
Tabela 6 - Implicaçôes positivas e negativas da utilizaçấo do áudio-livro.

\begin{tabular}{l|l|l}
\hline E1 & Leitura rápida & Aspectos negativos \\
\hline E2 & Leitura rápida & Desconhecimento da gramática e da ortografia \\
\hline E3 & Portabilidade, agilidade & Nenhum \\
\hline E4 & Não citou nenhuma implicação & Desconhecimento da gramática \\
\hline E5 & $\begin{array}{l}\text { Maior facilidade para compreender } \\
\text { o conteúdo da Búblia }\end{array}$ & Não encontrou nenhuma implicação negativa \\
\hline
\end{tabular}

Fonte: os autores.

Julgou-se ainda interessante analisar um fato que marcou a vida do participante que envolvesse um meio de acesso, partindo do conceito de valorização das experiências dos mesmos. A Tabela a seguir traz as respostas dos mesmos.

Tabela 7 - Descrição de uma situação marcante relacionada ao braille e/ou ao áudio-livro.

\begin{tabular}{c|l}
\hline E1 & "O acesso à literatura em braille e áudio (depois de ficar cego).” \\
\hline E2 & $\begin{array}{l}\text { "Como eu terminava a leitura em braille rapidamente, um professor me fez ler um } \\
\text { livro em braille do lado inverso (relatou, rindo, o participante)." }\end{array}$ \\
\hline E3 & $\begin{array}{l}\text { "Quando eu trabalhava com estética, ficava falando alto para estudar o conteúdo de } \\
\text { um concurso público e minhas clientes adoravam minha voz." }\end{array}$ \\
\hline E4 & $\begin{array}{l}\text { "Foi quando li o áudio-livro da história do Marly e Eu, pois tenho um cachorro } \\
\text { que é adestrado para ser cáo guia, entáo conforme a história ia passando eu fui } \\
\text { pensando nele e me emocionei muito." }\end{array}$ \\
\hline E5 & $\begin{array}{l}\text { "Em um áudio-livro que eu possuo em casa (da bíblia), está escrito em Josué } \\
\text { "enfrenta-te e tem bom ânimo" e é o que a gente tem que fazer. Mesmo sendo cego } \\
\text { náo ficar tristes. Devemos enfrentar, ter bom ânimo e Jesus nos ajudará, } \\
\text { é isso que eu percebo com todas essas coisas que eu vejo (o participante ri) que eu } \\
\text { vejo não, que eu ouço, claro." }\end{array}$ \\
\hline
\end{tabular}

Fonte: os autores.

\section{Conclusão}

Pode-se, prioritariamente, concluir que ambos meios de acesso estudados possuem suas implicaçóes positivas e negativas, de tal forma que as pessoas cegas tendem a optar por ambos. Mas, apesar disso, em termos de preferência, o braille prevalece drasticamente, mesmo que possam existir mais implicaçóes negativas em relação ao braille do que ao áudio livro.

Ao mesmo tempo, apesar de haver menos implicaçôes relativas sobre o áudio -livro, este se mostra mais relevante, pois infere diretamente no sucesso profissional dos indivíduos, considerando a sociedade em que vivemos. Neste sentido, é de extrema importância que as pessoas cegas se apropriem do sistema de escrita em braille, para que consigam realizar com sucesso atividades de escrita. 
Um fator que se acreditava que seria explicitado no decorrer da pesquisa é a preferência pelo meio de acesso de acordo com o tipo da cegueira, mas devido ao fato de ter-se um número maior de cegos adquiridos do que congênitos, bem como, ao pequeno número de participantes, não foi possível elucidar esta questão, deixando-a para futuras pesquisas.

Também é importante ressaltar o fato de que todos os participantes envolvidos se apropriaram do sistema de escrita em braille em uma instituição especializada para pessoas com deficiência visual, mas de acordo com Regis (2009), esta tendência possui probabilidade de mudar com o tempo.

Por fim, pode-se concluir que, de acordo com os resultados encontrados, independentemente das decorrências negativas do braille estar em maior número do que do áudio-livro, as pessoas cegas continuam preferindo o primeiro meio citado, de tal forma que é importante elaborar pesquisas que visem melhorar ou sanar as implicaçóes negativas do braille, tornando-o mais portátil, aumentando sua agilidade na hora da leitura, trabalhando a questão do desgaste manual das letras do alfabeto de seis pontos a partir do manuseio de seu usuário e, também, a quantidade de folhas em comparação com os textos impressos. Além disso, também é importante diminuir os efeitos negativos do uso do braille para que, futuramente, este seja cada vez menos utilizado, causando diferentes implicaçóes na qualidade da escrita das pessoas cegas, devido ao fato do áudio-livro não possibilitar o conhecimento gramatical do texto.

\section{Referências}

BARRAGA, N. Disminuidos visuales y aprendizaje: enfoque evolutivo. Madrid: ONCE, 1985.

CIERCO, J. El braille y las nuevas tecnologías. Entre dos mundos: revista de traducción sobre discapacidad visual, n. 19, p. 61-65, 2002.

DALLABRIDA, A. M.; LUNARDI, G. M. O acesso negado e a reiteração da dependência: a biblioteca e o seu papel no processo formativo de indivíduos cegos. Cadernos Cedes, Campinas, v. 28, n. 75, p. 191-208, 2008.

FRANCO, J. R.; DIAS, T. R. S. A pessoa cega no processo histórico: um breve percurso. Revista Benjamin Constant, Rio de Janeiro: n. 30, p. 1-9, 2005.

GARCIA, J. I.; CAÑADAS, D. P La formación de ciegos y discapacitados visuales: visión histórica de un proceso de inclusión. In: El largo camino hacia una educación inclusiva: la educación especial y social del siglo XIX a nuestros días: XV Coloquio de Historia de la Educación, Pamplona-Iruñea, 2009. Universidad Pública de Navarra, 2009. p. 453-462.

HERTLEIN, J. El braille: Requisito imprescindible para la enseñanza y formación de las personas ciegas. Revista Entre Dos Mundos, n. 12, p. 5-13, 1999.

LOWENTHAL, R.; ARAUJO, A. C. S. Transtornos Invasivos do Desenvolvimento e Comorbidades: Síndrome de Down e Deficiência Visual. Caderno de Pós-Graduaçáo em Distúrbios do Desenvolvimento, v. 6, n. 3,2006 .

MARTÍNEZ, J. M. Los Ciegos en la Historia. Madrid: ONCE, 1991.

MAZZOTTA, M. J. S. Educação especial no Brasil: história e políticas públicas. Cortez Editora, 2005.

PALETTA, F. A. C.; WATANABE, E. T. Y.; PENILHA, D. F. AUDIOLIVRO: inovaçōes tecnológicas, tendências e divulgação. Anais... Seminário Nacional de Bibliotecas Universitárias, XV. Unicamp: Campinas, 2007.

REGIS, M. C. A. S. Categorias Literárias, programas de áudio para o incentivo à leitura de deficientes visuais: um olhar transdisciplinar. Tese de Doutorado, Faculdade de Educação. USP. São Paulo, 2009.

REIS, M. X.; EUFRÁSIO, D. A.; BAZON, F. V. M. A formaçấo do professor para o ensino superior: Prática docente com alunos com deficiência visual. Educaçáo em Revista, Belo Horizonte, v. 26, n. 1, Abr. 2010. 
RUEDA, C. S. Utilización de la información contextual en la lectura braille. Entre dos mundos: revista de traducción sobre discapacidad visual, n. 19, p. 5-11, 1995.

SAMPIERI, R. H.; COLLADO, C. F.; LUCIO, P. B. O processo de pesquisa e os enfoques quantitativo e qualitativo. In: Metodologia de pesquisa. São Paulo: McGraw-Hill, 2006. p. 2-21.

TEMPORINI, E. R.; KARA-JOSÉ, N. A perda da visão: estratégias de prevenção. Arq. Bras. Oftalmol., v. 67 , n. 4, p. 597-601, 2004.

TORRES, E. F.; MAZZONI, A. A.; MELLO, A. G. Nem toda pessoa cega lê em Braille nem toda pessoa surda se comunica em língua de sinais. Educaçáo e Pesquisa, v. 33, n. 2, p. 369-385, 2007.

WARREN, D. H. Blindness and children: An individual differences approach. Cambridge University Press. New York, 1994.

\section{Nota}

${ }^{1}$ Pesquisa realizada na disciplina de Processos Investigativos I: planejamento do trabalho científico, sob a orientação das Professoras Maria Amélia Almeida e Márcia Duarte.

\section{Correspondência}

Ailton Barcelos da Costa - Universidade Federal de São Carlos, Centro de Educação e Ciências Humanas, Programa de Pós-Graduação em Educação Especial. Via. Wahington Luiz, Km 235, Monjolinho, CEP: 13565905 - São Carlos, São Paulo - Brasil.

E-mail: vivi.eesp@gmail.com - amanda_acsp@hotmail.com - pezorel@hotmail.com - ailton_barcelos@yahoo. com.br-ameliama@terra.com.br-marciaduar@yahoo.com.br

Recebido em 17 de janeiro de 2014

Aprovado em 18 de fevereiro de 2015 
